\title{
Theoretical Quality Management Frameworks in Today's Business: An Automobile Industry Application
}

\author{
Mahesh Raisinghani \\ TWU School of Management, \\ Denton, USA \\ mraisinghani@twu.edu
}

\author{
Juergen Georg Kaiser \\ Ericsson, \\ Stuttgart, Germany \\ kaiser bk@t-online.de
}

\section{Tamara Abdulovic TWU School of Management, Houston, USA \\ abdulot@sbcglobal.net}

\begin{abstract}
The quality paradigm today is an essential part of business in the U.S. as well as on a global scale. It took a long time to recognize the pivotal role of quality management for organizational excellence. Today, no one doubts the necessity of a systematic quality approach.

The evolution of Total Quality Management (TQM) and most of its derivatives can be traced back to the period when American quality pioneers developed quality management frameworks, taught them, and supported their application in the Japanese industry. The automotive sector is a prime example for quality management principles, illustrating both positive and negative implications of quality paradigms.

This paper focuses on the automobile industry and evaluates the different quality approaches common in this industry. As a result, the conclusion to be drawn is that, rather than implementing a rigid quality framework, it is more important to have a consistent and continuous quality approach, which is applied on all levels and involves all employees, incorporating the organizational functions with a holistic approach.
\end{abstract}

Keywords: Project Quality Management, Quality Management Frameworks, Automotive Industry, Six Sigma, Relationship and Compatibility among Different Quality Approaches

\section{Introduction}

Material published as part of this publication, either on-line or in print, is copyrighted by the Informing Science Institute. Permission to make digital or paper copy of part or all of these works for personal or classroom use is granted without fee provided that the copies are not made or distributed for profit or commercial advantage AND that copies 1) bear this notice in full and 2) give the full citation on the first page. It is permissible to abstract these works so long as credit is given. To copy in all other cases or to republish or to post on a server or to redistribute to lists requires specific permission and payment of a fee. Contact Publisher@InformingScience.org to request redistribution permission.
Quality management has emanated today as an essential and indispensible building block of business practices and strategies. Competitive markets demand efficient management, which cannot be envisaged without a functioning quality management system. Improved product quality that needs to remain consistently high, a focus on the customer, and reduced operational cost by optimizing quality assurance programs are the sali- 
ent ingredients for today's business excellence. In today's global markets, organizations missing implementation and integration of quality management into their business practices will eventually lose their competitive edge. The prevailing quality management systems used in the business world can all be traced back to the 1950s when quality peers, such as Deming and Juran, first established the quality paradigm.

The development of quality management is closely tied to the automobile industry, as many quality approaches were applied early on in the automobile sector and brought a mutual enhancement to both worlds. Toyota pioneered many quality principles, such as the origins of Total Quality Management (TQM), Just-In-Time Management, or Lean Management, and Ford can be seen as prime example for the effect of quality principles on business performance.

\section{Deming's 14 Points as Basis for TQM}

TQM is less a fixed and rigid quality framework than a company culture. Companies must commit to quality principles and approaches consistent with the company environment. The emphasis lies predominantly on goal oriented aspects, and while TQM itself does not determine a specific system about how to reach the goal, it measures the customer satisfaction through continuous improvements with the active participation of all employees (Dahlgaard, \& Dahlgaard-Park, 2006). The origin of TQM initiated from the pioneering work, laid out by Deming and Juran, which was further advanced by quality peers such as Ishikawa, Taguchi, Crosby (Saravanan, \& Rao, 2006), and Feigenbaum (Feigenbaum, \& Feigenbaum, 2005). To illustrate the fundamental importance of these pioneers, Deming's 14 Points for Management will be evaluated as unus pro multis.

The 14 Points for Management by Deming (Figure 1) represent a cornerstone for the evolution of quality management. Published only in the 1980s by Deming (1982), the underlying ideas emerged as early as the 1950s from his contributions in different ways, shaping many quality management advancements in most major quality approaches and serving as basis for major quality movements and theories. Illustrating the quintessence of Deming's understanding of quality management, the 14 Points for Management will be briefly outlined with a few words. The points represent a full-fledged quality philosophy, which comprehensively covers guidance and management strategies to be followed may senior leadership. Standing out among the points, is the basic prerequisite for an understanding that quality is a purely long-term undertaking and requires appropriate commitment with sufficient resource. The perpetual pursuit for quality must be adjusted to incorporate continually changing quality paradigms. Preeminent among these is a major focus on the continually evolving customer expectations, which tend to become more demanding and sophisticated. 
1 Create constancy of purpose toward improvement of product and service with a plan to become competitive and to stay in business

2 Adopt the new philosophy. We are in a new economic age. We can no longer live with commonly accepted levels of delays, mistakes and defective workmanship

3 Cease dependence on mass inspection. Require statistical evidence that quality is built in. (Prevent rather than detect defects)

4 End the practice of awarding business on the basis of price-tag. Eliminate suppliers that cannot qualify with statistical evidence of quality

5 Find problems. It is management's job to work continually on the system

6 Institute modern methods of training on the job

7 The responsibility of foremen must be changed from sheer numbers to quality. Management must prepare to take immediate action on reports ... (to remove) ... barriers such as inherited defects, machines not maintained, poor tools ...

8 Drive out fear, so that everyone may work effectively for the company

9 Break down barriers between departments. People in research, design sales, and production must work as a team ...

10 Eliminate numerical goals, posters and slogans for the workforce, asking for new levels of productivity without providing methods

11 Eliminate work standards that prescribe numerical quotas

12 Remove barriers that stand between the hourly worker and his right to pride of workmanship

13 Institute a vigorous program of education and retraining

14 Create a structure in top management that will push every day on the above 13 points

Figure 1: Deming's 14 Points, taken from "Benchmarking the challenge to quality program implementation" (Lee, Fawcett, \& Briscoe, 2002)

Quality must be incorporated into the design process by moving its focus to early stages of the production life cycle, thus eliminating the need for mass inspections. This means operational cost reduction when shifting from a reactive to a proactive mode. Deming emphasizes the need for quality management to build quality into the product. "Quality at the Source" means that every single employee is responsible for quality in every moment. Dedicated quality departments should be made redundant by this quality approach, since they are decoupled most of the time from internal matters of the production process and will never be as efficient in determining deficiencies.

Cost is an important factor in business competitiveness, but Deming points out that a management maxim focusing purely on cost reduction is too short-sighted. In contrast, a more holistic view in which quality is the prime driver for improving customer satisfaction will eventually lead to more sustainable long-term business conditions. Applying this principle specifically to supplier-buyer relationships, a focus away from price competition alone, and a shift towards quality strategies fostering long-term supplier-buyer relationships, will result in reduced quality variability and significant quality gains. 
Implementing these quality strategies into effective operational practices comprises a focus on employee empowerment. Comprehensive on-the-job training programs, as well as the cultivation of a supportive environment allowing continuous learning, are both essential measures to assure workers will be capable of doing their jobs both effectively and efficiently. Simultaneously, quality improvement demands that leadership instill a sense of enthusiasm and an elevated motivation to all employees, in order to create a sense of coherence in pursuing a common quality goal. Feedback is essential in leadership management and will drive out destructive fears of change and enhance employee creativity, thus supporting pro-activeness commitment. Employees must be given as much responsibility and autonomy over their tasks as possible. Fixed predefined work standards are counterproductive when maintaining quality status quos, because they do not reflect continuous improvement and therefore lack a proper stimulus for employees to exceed beyond implemented benchmarks. The ultimate goal in employee management is to furnish a working environment, which generates employee pride and commitment.

During the product life cycle, a basic principle listed by Deming for quality improvement is open communication between the departments. This will lead to a product design in which focused intra-departmental teams are engaged in parallel, rather than with the inferior sequential departmental approach of product design in which only one department at a time is occupied with the product. Hollow slogans, putting pressure on the employees, estrange them from the common goal of the company rather than aligning and motivating them. They are inconsistent with constructive feedback and do not convince employees to be willing to take responsibility. Furthermore, they ignore that many quality problems arise from inefficient system implementations, rather from employee performance. Finally, one of the basic truths of management is quality management must be a part of the daily work of each single employee.

\section{The Concept of TQM}

Although the term TQM was coined only after the reemergence of the quality movement in the U.S. in the 1980s, its basic principles date back to the early activities of the quality founders, Deming and Juran. Deming pioneered the quality paradigm in the 1940s. Japanese companies were among the first to seriously apply quality as a fundamental concept. Deming and Juran were both active in Japan long before the importance of their contributions were rediscovered in the U.S. the 1980 s.

When analyzing the field of quality theories today, there are different areas and aspects which have been developed. While the quality paradigms of TQM had been advanced and refined, they continually serve as foundation for newly emerging quality theories, such as most trends of quality standards as well as the appearance of the national Quality Prizes.

The building blocks of TQM, as illustrated in Figure 2 (Mukherjee, \& Kachwalka, 2010), are the objectives an organization should aim for in order to permanently improve the quality aspects on the way toward industry leadership. 


\section{Eight Building Blocks of TQM}

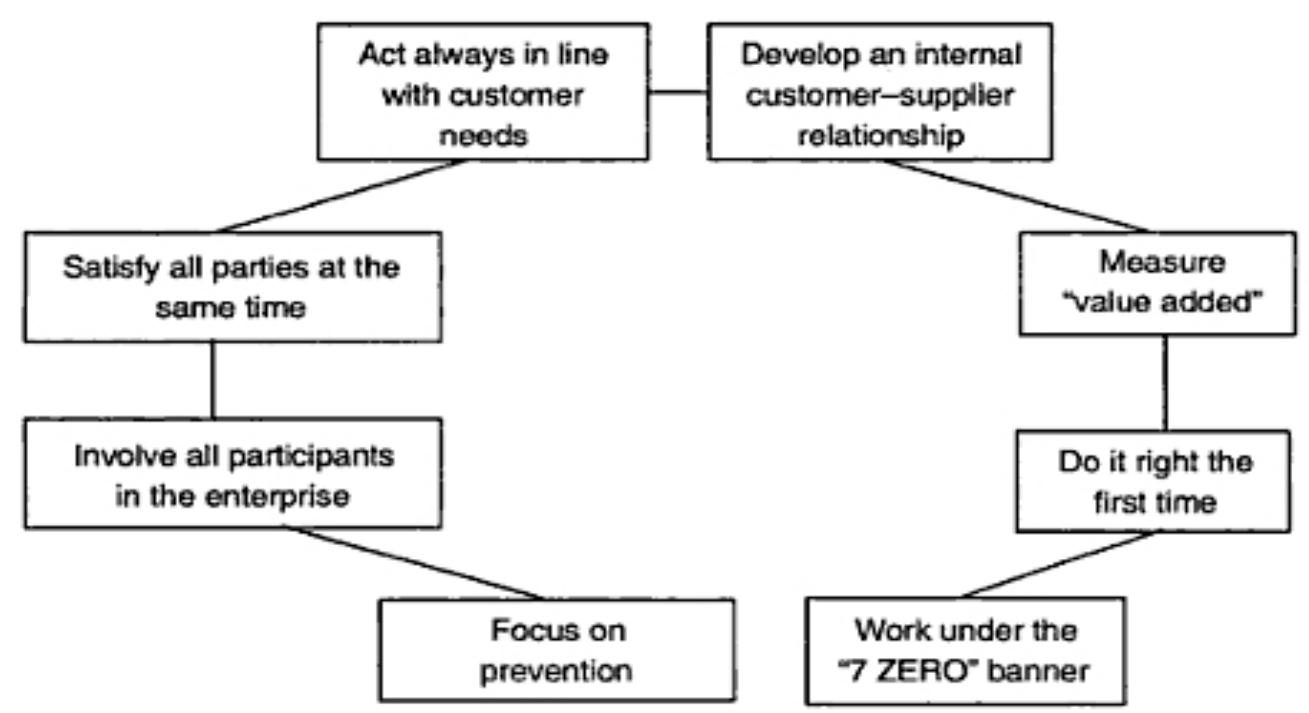

Figure 2: TQM and its Building Blocks (Mukherjee, \& Kachwalka, 2010)

Market excellence is achieved through customer satisfaction. The customer's needs and wants serve as the guiding principle for all of the company's goals. Global competition will not allow the organization's survival, if it is not focused on fulfilling customer needs. The development of an internal customer supplier relationship, as the interface into the subsequent process for each process, is regarded under a customer relations perspective, entailing the appropriate ramifications, which are derived from a need to satisfy the customer. Measurement is an important prerequisite for improvements in TQM. The value of each process or step must be measurable, and measurements should be conducted regularly. By analyzing the value of the product before and after the process, the created surplus of the process can be measured. This maxim is expressed with the TQM motto, "Do it right the first time." Cost increases to multiple values, the later the defects are detected and corrected in the process chain. This perception tries to minimize the waste of resources, which goes in hand with a focus on prevention. Repetition of mistakes is not acceptable, and quality is only assured if the root cause of problems or defects is found and eliminated.

The building block of the seven zeros, as illustrated in the diagram, refers to the seven mudas, a Japanese term meaning waste, derived from the Toyota Production System. For TQM, muda, or waste, must be eliminated on several levels: negative thinking refers to the whole company culture, removing excessive inventory and achieving zero delays, zero paper are directed towards improving organizational processes, while zero downtime, zero defects and zero accident are the goals to be achieved. Involving all participants is a recurring theme in quality management, pervading all quality systems. Satisfying all parties at the same time refers to expectations to excel in all relations with the customer, the employees, the suppliers, and moreover with the shareholders as well as society as a whole. The following list highlights the principles of TQM:

- Organization needs a vision and a goal, clearly defined with a mission

- The quality paradigm is customer centered

- The employee is an asset and is the driving force for success

- The organization's processes are directed towards continually improving the quality 
- Tools and techniques must be available to support improvements

- Benchmarking as a tool for quality improvements

- Customer Market Evaluation as a crucial tool supporting the customer-driven approach

Reiterating the importance of people, processes, and systems for quality initiatives to succeed, the building blocks of TQM (Department of Trade and Industry, n.d.) are illustrated in Figure 3 as processes, people, management systems, and performance measurement. The responsibility of implementing process quality lies with the people who will be the decisive success factor. People carry out the processes and by focusing on quality measures, combining improvement activities with commitment and recognition from the leaders, the prerequisite climate is prepared to facilitate the success of Quality Management Systems. Once the strategic direction for the organization's quality journey has been set, it needs Performance Measures to monitor and control the quality standards in order to sustain the quality strategy.

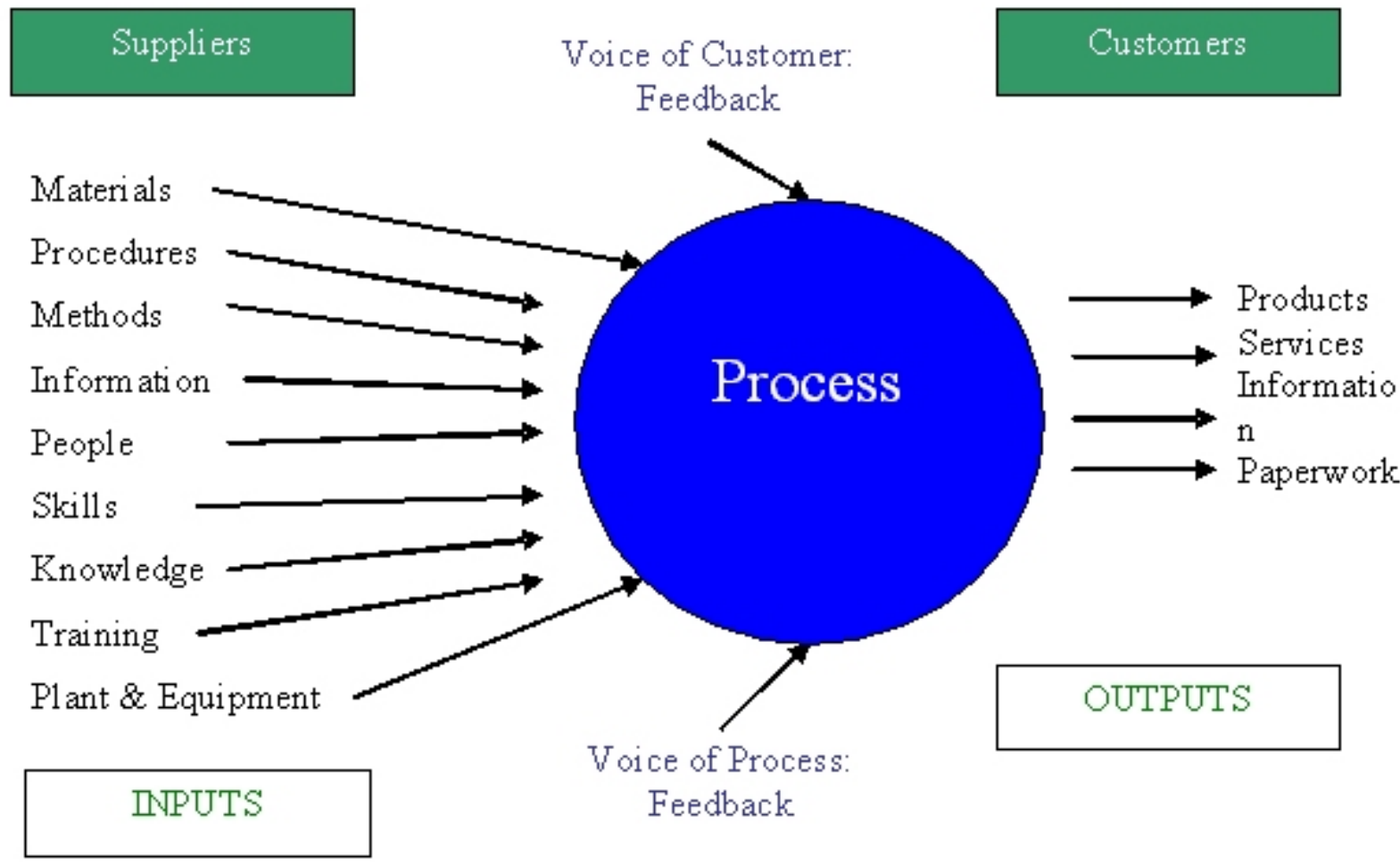

Figure 3: A view on TQM accentuating people, processes, and systems

(Department of Trade and Industry, n.d)

\section{TQM Facing the Challenges of Operational Excellence}

The effect of TQM on business value, product innovation, and organizational excellence is a controversial topic among scholars, and several research studies have been conducted to examine the interdependence of quality on business results. A major review and seminal study on TQM and its effect on business excellence was conducted by Powell in 1995. The study evaluated a vast amount of data available at that time, and it concluded that there is no obvious correlation between the pure application of TQM frameworks and an improved operational performance. TQM has the potential to improve performance, but it is by no means a self-selling item. Powell suggests that for consistent operational excellence, companies must focus their efforts in creating a company culture based on quality principles, rather than imitating TQM methodologies (1995). 
A more recent empirical study by Liang-Hung, \& Iuan-Yuan (2006) examines the effect of product quality on product innovation at various automakers in Asia, the USA and Europe. The study determined a strong relationship between product quality and the effective innovation capabilities of the automakers. When applying the issued patents as indicator of product innovation, and the problems-per-100 vehicles (PP100) metric as indicator for quality, Figure 4 indicates a resulting linear regression function. The linearity of the regression plot displays an equivalence of all quality systems, since product quality is achieved by various quality system approaches. Furthermore, the study does not make assumptions about the type of specific quality system, such as Six Sigma, TQM, or simply the adherence to quality standards such as ISO 9001. Thus, the result demonstrates the need for one quality system, if an automaker aims to stay at the front of innovation. It is interesting to note that geographical origin affects innovation more than anything else, as displayed by the higher value function for Asian producers compared to Western ones. The authors attribute the cause to a different company culture but not to quality systems per se. Further research is required to verify this analysis, since one factor could be a higher quality maturity due to the longer and more consequent implementation of quality systems in Japan, where Toyota began applying its TPS as early as the 1950s.

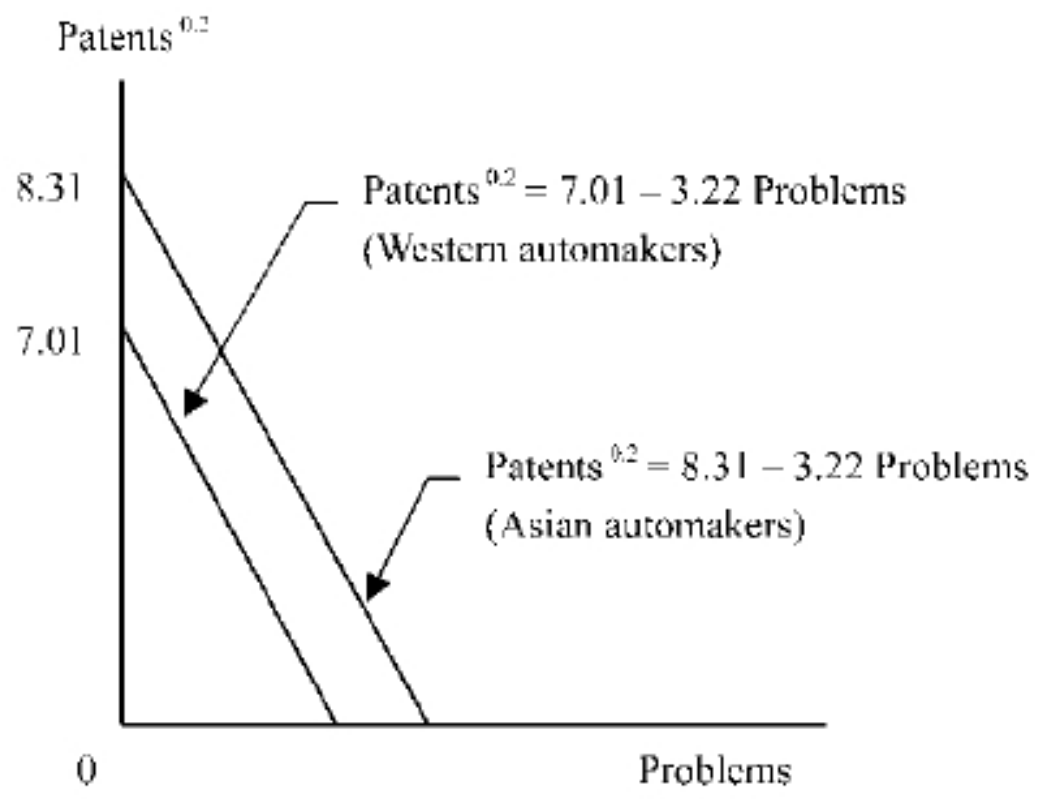

Figure 4: The effect of product quality on product innovation (Liang-Hung, \& Iuan-Yuan, 2006)

\section{Relationship and Compatibility among Different Quality Approaches}

Several scholars have pursued the question of compatibility between different quality approaches, which can be concurrently prevalent within organizations. While quality management systems, such as ISO 9001 and their derivates, are basically goal oriented quality frameworks, which do not prescribe processes but require the organizations to achieve standards, questions arise as to what degree they are consistent with full quality management systems. These full quality management, such as Six Sigma systems, on the other hand, prescribe specific techniques and approaches. Several studies have been conducted, such as a research paper by Chin-Hung (2009), elaborating on the compatibility of Six Sigma with the quality management system ISO/TS 16949, which is a globally accepted substandard for the automobile derived from ISO 9001. The 
ISO/TS 16949 framework focuses on continuous improvement and improving customer satisfaction. Six Sigma is the collection of processes that utilize statistical quality tools to achieve better results in terms of quality. The goal is to eliminate defects below the limit of 3.4 parts per million and reduce variability in process outcomes. By comparing this definition of TQM with the ultimate objectives of the lean producers as described above, it is obvious there are no contradictions between the two objectives. This is not a coincidence, because the roots of TQM can be traced back to the Japanese quality evolution in which Toyota was one of the pioneering companies.

\section{The Toyota Quality Approach}

Toyota practiced the philosophy and principles of TQM as early as the 1950s. Toyota pioneered many quality business principles, such as Just-In-Time and Lean Management, which today are essential core principles of almost any production system in all industries worldwide. Toyota managed to convince critics with the perseverance of its long-term strategy, eventually surpassing most of its peers and becoming the most profitable mass automotive producer in the world in just a few decades.

To understand the system underlying Toyota's lean production approach, the Toyota Production System (TPS) requires the acceptance of a totally new perspective on production systems and quality concepts. It is not sufficient to learn the lean tools and techniques. In order to succeed, all stakeholders in the company from the manager down to the last worker on the production line need to grasp the philosophy. TPS is a culture rather than a set of tools and techniques. Companies have tried to adopt quality approaches and tools devised by Toyota, such as Kanban (used for managing the flow and production of materials), Andon (a control device in the production area enabling workers to stop processes if defects occur), and failed to improve their production systems. Continuous improvement of the production system and a focus on the people who stand behind the system requires active participation and communication by all participants. The system needs to be designed in a way to support the employees in improving the system. It enables the workers to participate by emphasizing the necessary education, training, and rewards. The lean tool of 5S (sort, stabilize, shine, standardize, and sustain) is a prime example of Toyota's philosophy, in which "sustain" stands for the long-term alignment of all activities.

The 14 Principles of the Toyota Way, assembled as an executive summary by Jeffrey Liker, characterizes its specificities and illuminates the cultural approach behind TPS (2003, pp.37-41). The principles are divided into the four major pillars sustaining the system, which are determined as long-term strategy, goal orientation of TPS tools, value creation by empowering the employee, and continuously solving root problems:

- Principle 1 Base your management decisions on a long-term philosophy, even at the expense of short-term financial goals.

- Principle 2. Create a continuous process flow to bring problems to the surface.

- Principle 3. Use "pull" systems to avoid overproduction.

- Principle 4. Level out the workload (heijunka). (Work like the tortoise, not the hare.)

- Principle 5. Build a culture of stopping to fix problems, to get quality right the first time.

- Principle 6. Standardized tasks and processes are the foundation for continuous improvement and employee empowerment.

- Principle 7. Use visual control so no problems are hidden.

- Principle 8. Use only reliable, thoroughly tested technology that serves your people and processes. 
- Principle 9. Grow leaders who thoroughly understand the work, live the philosophy, and teach it to others.

- Principle 10. Develop exceptional people and teams who follow your company's philosophy.

- Principle 11. Respect your extended network of partners and suppliers by challenging them and helping them improve

- Principle 12. Go and see for yourself to thoroughly understand the situation (genchi genbutsu).

- Principle 13. Make decisions slowly by consensus, thoroughly considering all options; implement decisions rapidly (nemawashi).

- Principle 14. Become a learning organization through relentless reflection (hansei) and continuous improvement (kaizen).

Several studies were conducted, evaluating the Toyota approach as driver for quality improvements. Most of them identify many of Toyota's principles in influencing product quality as well as customer satisfaction. Lightle, Rosenweig, and Talbott (2003) highlight employment empowerment and management commitment as two outstanding basic catalysts providing Toyota with a competitive edge over its U.S. peers. A larger study executed by Regassa and Ahmadian (2007) uncovered several principles based on the TPS as a driver for efficiency, putting Toyota well ahead of the big three U.S. car manufacturers. The TPS was identified as supporting Toyota's business excellence on the basis of the Kaizen principle, Toyota's philosophy of continuous improvement, which is incessantly focused on eliminating inefficiencies, coined as muda (waste). As a second major factor pushing Toyota ahead of its competition, the authors identified the JustIn-Time Production, which helps the company gain efficiency and facilitates the early detection of quality defects. As a consequence of this quality approach to business performance, comes the increased financial performance of Toyota compared to GM as well an increase in U.S. market share development, which is highlighted with Figures 5 and 6.

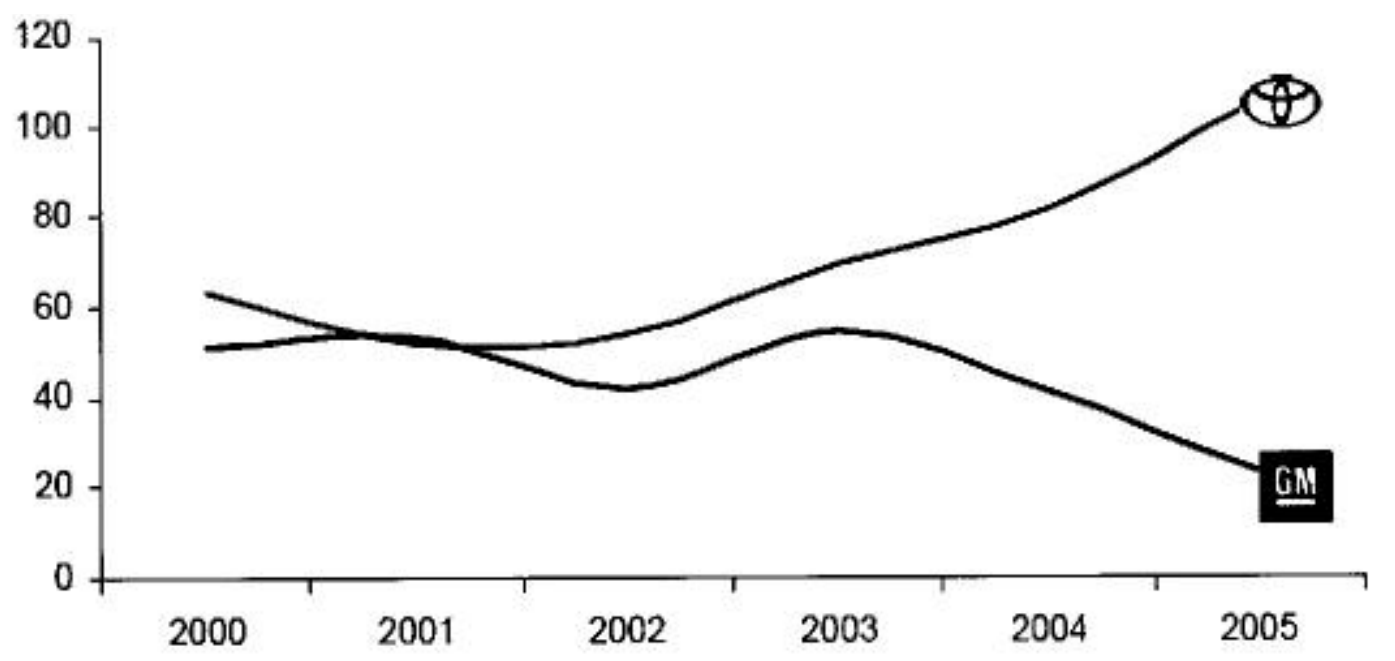

Figure 5: Financial Performance between Toyota and GM (Regassa, \& Ahmadian, 2007) 


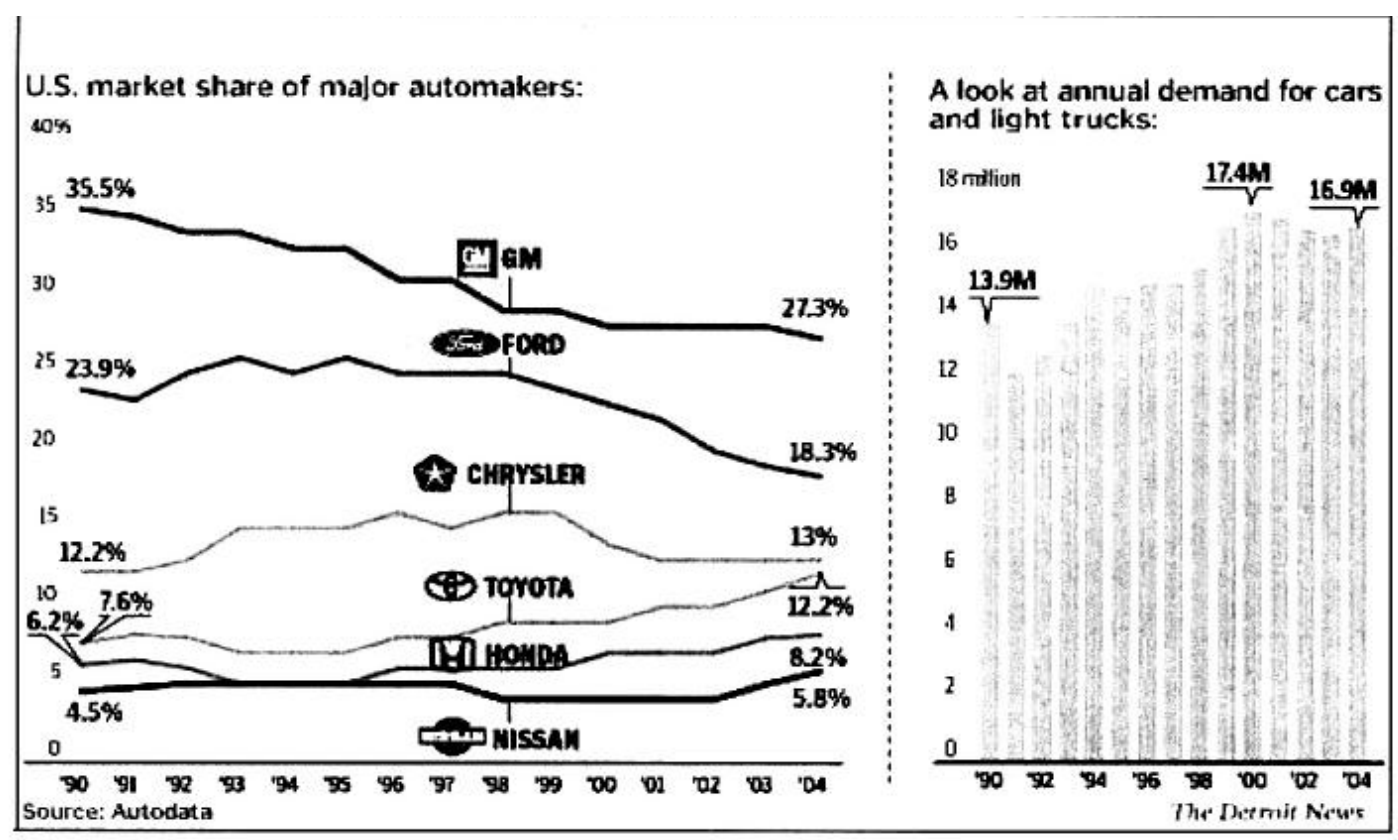

Figure 6: Increasing Market Share of Toyota (Regassa, \& Ahmadian, 2007)

\section{Toyota's Recent Troubles}

Recently, the image of Toyota suffered from several setbacks, casting doubts on the once so successful Toyota Way. Car accidents, the recall of millions of cars, and even an interrupted production process for one week uncovered unprecedented quality deficiencies in the current Toyota Process (Wharton University of Pennsylvania, February, 2010). Analyzing the problem in depth revealed a shift from its focus on quality improvements according to their own TPS, towards cost reductions and the implementation of a tremendous expansion plan, which exceeded the capabilities of TPS. The growth coupled with the cost cutting measures itself was not the only cause, rather internal factors such as increased production lines, new production facilities, and a greater model variety contributed to the growing complexity as did outside factors in the form of social pressure and market demand (Wharton University of Pennsylvania, March, 2010).

Although Toyota did not try to hide the problems, the passive approach was perceived negatively in the U.S. It took a slowly adopted learning process for the company to encounter the negative publicity. Consequently, the media reaction vastly exaggerated the situation, trying to malign the company processes as a whole. Liker (2010) points out that most of the public reaction is based on emotions without substantive facts and emphasizes the underlying strength of the Toyota's quality model. According to Liker, Toyota survived the recession without layoffs and took advantage of the current economic slowdown to improve on quality and safety. Workers who were not needed in the production process were reeducated in the quality production system (2010). Due to the offset between the current quality improvements and its effect on customer market and ensuing quality perception, Liker points further out that Toyota might have the quality problems already under control.

\section{Quality Prizes as Drivers for Business Quality}

Primus inter pares among quality awards, the Japanese Deming Prize (DP), was already introduced in the 1950s in Japan as the very first award of this kind, thus indicating the relevance of quality for business improvements in Japan. The prize, named in honor of Deming's achieve- 
ments to the Japanese industry, is awarded to companies that accomplish outstanding achievements in the field of quality. It took until the 1980 s for both the U.S industry and politics to realize the importance of quality management on product improvement, and this came only after Japanese imports displayed a superior product designs. As a consequence, the Malcolm Baldrige National Quality Award (MBNQA) was established in 1987 as a concerted response by the U.S. government to raise the general awareness for quality in the U.S. industry. Since then, the MBNQA is given to U.S. companies, which satisfy certain quality criteria. It is devised as a competition, in which each year one company per category wins.

According to Kumar (2007), both the Deming and the MBNQA quality awards base their scope on TQM concepts with an emphasis on their country's socio-cultural conditions. The awards are arranged around the seven fundamental management principles of leadership, strategic planning, customer and market focus, information and analysis, human resource focus, process management, and business results. The differentiating elements can be explained predominantly by the diverse cultural backgrounds of the countries as taken from Hsien and Kay (2003): The DP is more process-oriented and puts less emphasis on managerial practices and decisions. Leadership by example, for instance, is a quality element which is deeply rooted in the Japanese tradition.

The focus of the MBNQA is directed toward business results, as illustrated in Figure 7 taken from the National Institute of Standards and Technology [NIST] (2010). In order to win, organizations must present outstanding achievements in financial performance, customer satisfaction, customer retention, product performance, service performance, productivity, supplier performance, or public citizenship. The performance levels must be achieved consistently and must be among the best of their peers. The fact that the award is result driven is underpinned by the relative weight of 25 to $45 \%$ of the total score.

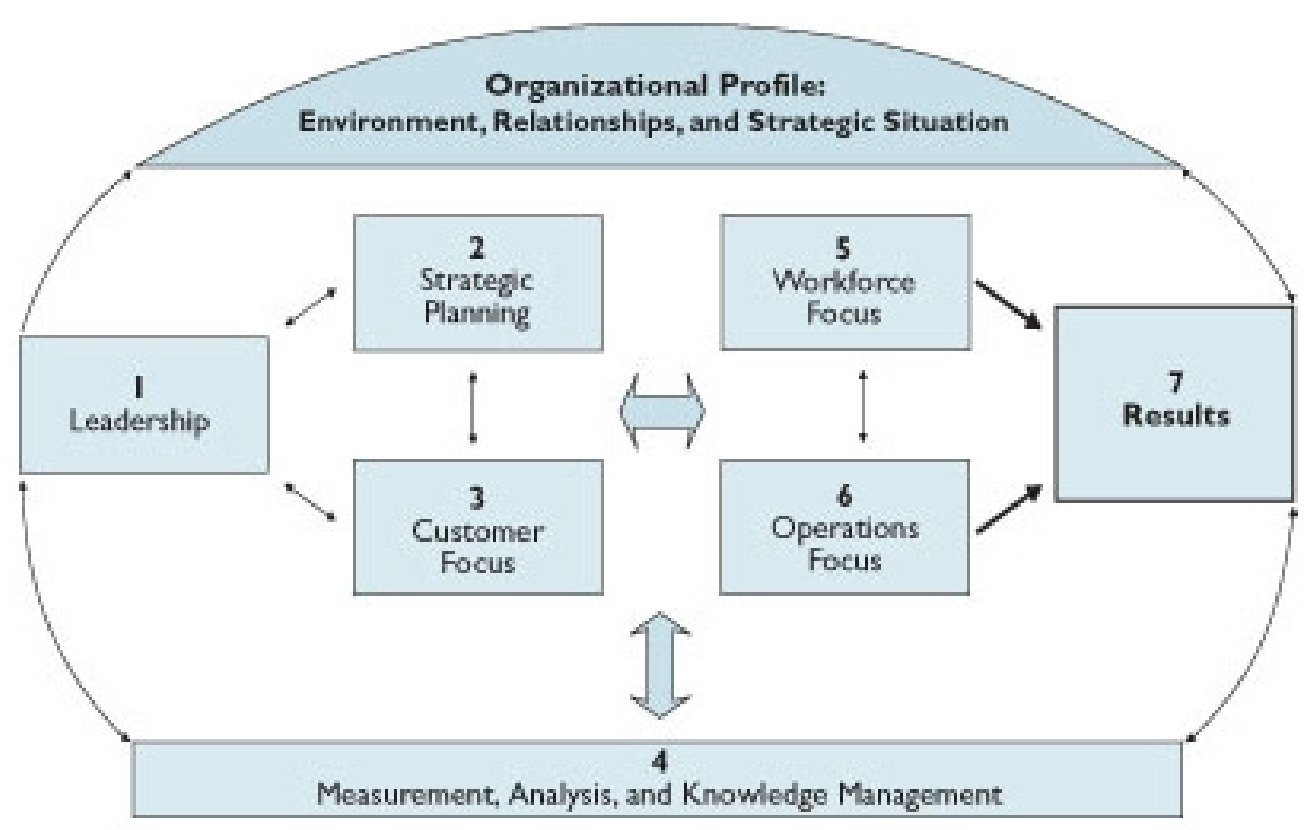

Baldrige Criteria for Performance Excellence Framework

Figure 7: Result Driven Performance criteria of the MBNQA (NIST, 2010) 
The criteria of the award are non-prescriptive and adaptable. The criteria do not predetermine which tools, techniques, or process the organizations should use to reach their goals (NIST, 2010). Baldrige criteria focus on the alignment of goals and processes, which should encompass the entire organization. The companies should incorporate strategic processes and measures that are focused on attaining the company goals. Consistency of purpose should be harmonized with innovation support. The fundamental learning paradigm should be a cohesive element in aligning strategic objectives with implementations on the operation level. Goal driven diagnosis is a fundamental criterion. Among the assessment dimensions are the approach, deployment, and results categories. These three categories define the methods for identifying performance objectives, implementing them, and assessing the outcomes. This approach allows the company to evaluate its strength and identify areas for improvement. Finally, the MBNQA focuses strongly on the results of the company processes. The prize categorizes four different areas of results, such as customer-focused results; financial and market results; human resource results; and organizational effectiveness results.

\section{The Influence of Quality Awards on Organization Performance}

The elevated publicity of quality prizes, triggering a large number of companies to compete for quality awards, have induced a large array of research, focusing predominantly on the impact of quality prizes on organizational performance. The researchers are trying to determine a correlation between winning a quality prize and certain quality criteria. The crucial question behind the research is if the widespread support and public focus is really justified and a competitive advantage in terms of business attributes is generated, which will be sustained for long-term periods. One significant research project was conducted by Iaquinto, which evaluated the long-term performance of Japanese DP winners, of which one third consisted of automobile suppliers participating to the Toyota Production System (1999). Interestingly, the study concluded a predominantly negative effect of winning the award on long-term business performance. At first glance this seems contradictory to common quality understanding and would undermine the support by many governments for similar programs in order to foster national industrial competitiveness. Analyzing the findings in more detail, the result shows failure stemming from management immaturity and lack of quality culture. Companies, who won the DP without having implemented pervasive quality framework, such as TQM, and focusing too narrowly on the DP competition, harmed their company by deviating vital resources from the ongoing business processes, thus putting the employees even more under pressure, while diluting the approach to truly integrate quality aspects into business practices (Iaquinto, 1999). The conclusions can only be to generate definite guidelines for companies, which must focus on a genuine pursuit of quality management rather than following unsustainable goals such as one-time quality prize competitions.

\section{Six Sigma as a Quality Approach}

"Six Sigma is a highly disciplined process that helps us focus on developing and delivering nearperfect products and services" (GE.com, 2010). This definition of Six Sigma by one of its foremost promoters, General Electric (GE), illustrates the whole philosophy behind it. As a response to the increasing awareness by the U.S. public and industry, triggered by the Japanese quality superiority over the U.S industry, quality moved into the focus of business strategists. The book Quality is Free by Philip Crosby marked an important step of the development process, presenting a 14 step approach aimed at quality improvements with the ultimate goal of zero defects (Crosby, 1979). Motorola adopted the idea in the late 1980s and advanced it, creating the concept of Six Sigma. Motorola devised Six Sigma as an aggregation of statistical tools, based on the principles of process capability and product specifications, which evolved into the statistical con- 
cept of defects per million opportunities (DPMO) and was aimed at finding inefficiencies in product development processes (Folaron, 2003). The name was derived from the goal to allow six standard deviations between the process mean and the specification limit, thus reaching less than 3.4 defects per million parts. GE, under the helm of Jack Welch, went a step further to establish Six Sigma as the company's mandatory and all pervasive company culture. The concept of continuous quality improvements focused on driving down defects both in production and design and was refined with the underlying principle of DMAIC (Define, Measure, Analyze, Improve, and Control). The concept provided an effective quality management approach, and it was due to the famous success stories of Motorola and GE, which both claimed to have increased quality and process efficiency drastically. Motorola, for instance, claims to have saved $\$ 17$ billion from 1986 to 2004, (Motorola University, 2005). Six Sigma was also eventually adopted in the automobile industry, with Ford as the most prominent example. Ford, which had previous experience in TQM approaches, was able to profit from Six Sigma after it experienced increasing issues with quality management approaches.

\section{Assessing the Quality Approach by Ford}

Ford is a prime example in reflecting the quality approach of the U.S. automotive industry. Ford introduced TQM in the 1980s as a response to the superior Japanese car imports. TQM was focused on quality processes at all company levels, which had to be strictly followed, constantly improved, and evaluated via customer quality satisfaction surveys, emphasizing a customer driven approach. The results were huge quality improvements, and in 1986 Ford became the most profitable U.S. automotive company (Gabor, 2001). After Ford had received a substantive success with its TQM program by the mid-1980s, business focus shifted once again towards cost savings. The leading perception was that with the positive achievements from the applied TQM programs, the quality problems had been solved and the programs could be concluded. Consequently, quality levels declined, and Ford experienced major quality setbacks. Customer satisfaction lagged the competition during the 1990s again. The lesson from these experiences could be identified with lack of continuity as the major obstacle to attaining sustainable elevated quality standards. As Subir Chowdhury, a quality strategy expert had stated, "U.S. automakers had so much confidence, they felt they had achieved quality and didn't need to focus on it anymore," (Gabor, 2001).

To overcome these deficiencies, Ford decided beginning with 1999 to overhaul its quality process, this time adopting Six Sigma as an enhancement to their former TQM philosophy (Gabor, 2001). Six Sigma was seen as a good way to integrate innovation with marketing needs, while keeping the focus on costumer orientation. By adding a customer driven Six Sigma Process, quality was taken a step further, strengthening the design and engineering analysis process (Scheid, 2010). With the DMAIC process, as explained above, problems can be detected and corrected early on, which is further supported by newly developed virtual tools. The success, quantified by Ford with a decrease in $60 \%$ of the warranty repair rate, is based on several premises. Among the foremost factors is that if processes do not undergo radical changes, utilizing the tools of Six Sigma is not sufficient. Ford pursued an overall strategy which is founded on two irrevocable pillars: achieving consistency in the process improvements as the basis for change and focusing intensely on customer satisfaction. Six Sigma implementation was furthermore dependent on the establishment of cross-functional groups of engineers, plant management, and production specialists, with the emphasis on problem solving, predominantly based on skills gained through Six Sigma training. The selection of Six Sigma projects is based on their relevance in regard to customer satisfaction, their expected quality improvements to achieve at least a reduction in defects by at least 70 percent, and a cost-reduction goal averaging more than $\$ 250,000$ (Scheid, 2001). 
The Ford DMAIC cycle, to be followed by Six Sigma quality experts, Black Belts, consists of the following steps (Paton, 2001):

- Defining the scope of the project and identifying the customer involvement and what matters to them.

- Measuring involves the development of process measures facilitating the performance evaluation of the process. Current process characteristics need to be collected to enable assessment of the desired process performance. The Black Belts need to know what the process is, including the entire dependencies. Common tools used for this process are process mapping, cause-and-affect diagrams, failure mode and effects analysis, gage $\mathrm{R} \& \mathrm{R}$, and graphical techniques.

- Analyzing requires the determination of the root causes of process variation by prioritizing the input variables according to their impact on process deviation. Process mapping, graphical techniques, multivariate studies, hypothesis testing, and correlation and regression analysis are among the used tools for this approach.

- Improving the processes relates to the identification of solutions to best address the problems, which utilizes process mapping, design of experiments, simulation, and optimization to generate cost-benefit analysis, validation of problem solutions, and the implementation plan.

- Controlling, as the final stage, completes the improvement process and includes controls, which assure a sustainable gain in the processes.

Based on the principle of quality improvement, Six Sigma is furthermore focused on improving customer satisfaction by applying methods such as the process of Quality Function Deployment (QFD) and Taguchi's method of Design of Experiments (DOE), encompassing product design and robust design (Foster, 2010, pp. 419-426). Figure 8 illustrates the applicability of Six Sigma to the global supply chains of the U.S. automakers, highlighting the pervasive application of Six Sigma throughout the entire supply chain. The focus on reducing the process variation, based on customer needs and expectation surveys, will need to extend the approach of preliminary design, prototyping, and field-testing with each tier of suppliers (Bandyopadhyay, \& Jenicke, 2007). 


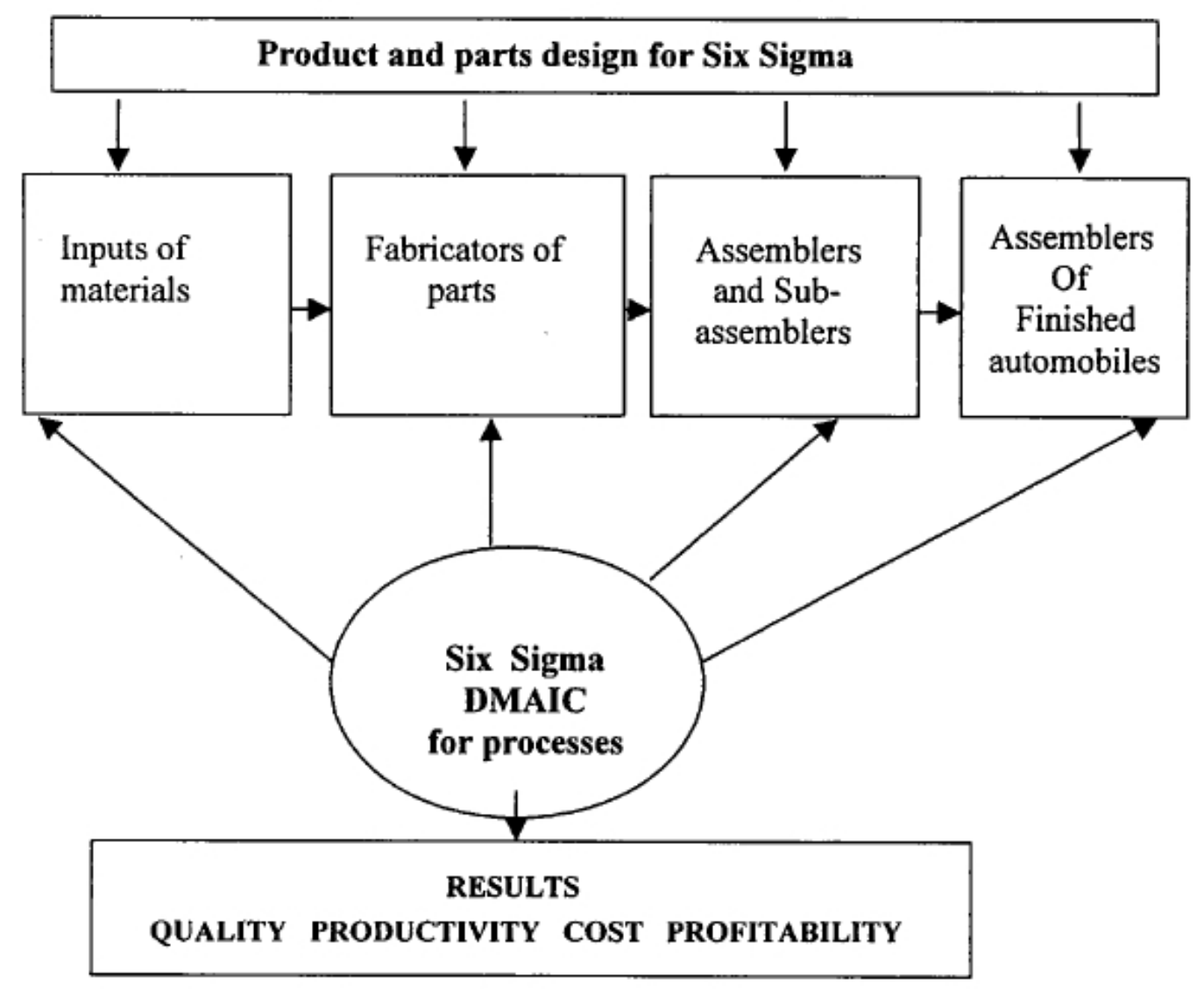

Figure 8: A model for Six Sigma approach to design and process improvement in automotive supply chains (Bandyopadhyay, \& Jenicke, 2007)

\section{Conclusion}

As this case study has revealed, the implementation of a consistent and sustainable quality approach is the foundation for process improvements, especially in the automotive industry. This paper has further shown the broad range of different quality approaches available and followed by today's automotive companies, suggesting the applicability of all ubiquitous theoretical quality frameworks. As the examples of Toyota and Ford have shown, the methods for reaching the quality goals are subordinate to an all-encompassing company philosophy and a culture, which assures management involvement and fosters the commitment of all employees. Quality frameworks applied on all levels, involving all workers with a holistic approach, and focusing on sustainability, were the factors that helped the companies achieve operational excellence.

If, on the other hand, management was only interested in implementing a rigid quality framework, then this was perceived as a pure tool, lacking both commitment and practices for employee empowerment and additional process adjustments. No long-term organizational gains were detected in these cases. Companies pursuing this approach either fared worse than before or lost their business improvements shortly after the processes were implemented.

\section{References}

Bandyopadhyay, J., \& Jenicke, L. (2007). Six Sigma approach to quality assurance in global supply chains: A study of United States automakers. International Journal of Management, 24(1), 101-107. Retrieved from Business Source Complete database. 
Crosby, P. (1979). Quality is free. New York: McGraw-Hill

Chin-Hung, L. (2009). Effect of ISO/TS 16949 on Six Sigma: The empirical case of Taiwanese automobile and related industries. Total Quality Management \& Business Excellence, 20(11), 1229-1245. doi:10.1080/14783360903247502.

Dahlgaard, J. J., \& Dahlgaard-Park, S. M. (2006). Lean production, six sigma quality, TQM and company culture. The TQM Magazine, 18(3), 263-281. Retrieved September 19, 2010, from ABI/INFORM Global. (Document ID: 1127240191).

Deming, W. E. (1982). Out of the crisis. Cambridge, MA: Massachusetts Institute of Technology Press

Department of Trade and Industry. (n.d.). The building blocks of TQM. Retrieved October 20, 2010 from http://www.zarate-consult.de/kosvet3/m5/KEET_M5_LU2_L1/the building_blocks_of_tqm.html

Feigenbaum, A. V., \& Feigenbaum, D. S. (2005). What quality means today. MIT Sloan Management Review, 46(2), 96. Retrieved September 19, 2010, from ABI/INFORM Global. (Document ID: 813908221).

Folaron, J. (2003, August). The evolution of Six Sigma. Retrieved October 7, from http://asq.org/pub/sixsigma/past/vol2 issue4/ssfmv2i4folaron.pdf

Foster, S. T. (2010). Managing quality: Integrating the supply chain. Upper Saddle River, NJ: Pearson Prentice Hall

Gabor, A. (2001, June 13). Quality revival, Part 2: Ford embraces Six Sigma. New York Times (Late Edition (east Coast)), p. C.5. Retrieved October 24, 2010, from ProQuest National Newspapers Core. (Document ID: 74042886).

General Electric Company. (2010). What is Six Sigma? Retrieved October 20, 2010 from http://www.ge.com/sixsigma/makingcustomers.html

Hsien, H. K., \& Kay, C. T.. (2003). Managing for quality in the USA and Japan: Differences between the MBNQA, DP and JQA. The TQM Magazine, 15(1), 14-24.

Iaquinto, A. L. (1999). Can winners be losers? The case of the Deming prize for quality and performance among large Japanese manufacturing firms. Managerial Auditing Journal, 14(1/2), 28-35. Retrieved October 24, 2010, from ABI/INFORM Global. (Document ID: 86065941).

Kumar, M. R. (2007). Comparison between DP and MBNQA: Convergence and divergence over time. The TQM Magazine, 19(3), 245-258. Retrieved September 15, 2010, from ABI/INFORM Global. (Document ID: 1363482131).

Lee, T. N., Fawcett, S. E., Briscoe, J. (2002). Benchmarking the challenge to quality program implementation. Benchmarking: An International Journal, 9(4), 374-387.

Liang-Hung, L., \& Iuan-Yuan, L. (2006). Product quality as a determinant of product innovation: An empirical analysis of the global automotive industry. Total Quality Management \& Business Excellence, 17(2), 141-147. doi:10.1080/14783360500450434.

Lightle, S., Rosenweig, K., \& Talbott, J. (2003). Why Toyota and Honda topped the 2002 J.D. power quality study. Cost Engineering, 45(12), 6-8. Retrieved October 24, 2010, from ABI/INFORM Global. (Document ID: 522801861).

Liker, J. K. (2003), The Toyota way: 14 management principles from the world's greatest manufacturer (1st ed.). New York: McGraw-Hill

Liker, J. K. (2010, January 28). Toyota's lost its quality edge? Not so fast. Business Week. Retrieved October 4, 2010 from http://www.businessweek.com/bwdaily/dnflash/content/jan2010/db20100128 907800.htm

Motorola University. (2005). About Motorola University: The impact of Six Sigma. Retrieved October 28, 2010 from http://web.archive.org/web/20051106025758/www.motorola.com/content/0,3081,00.html 
Mukherjee, P. N., \& Kachwalka, T. T. (2010). Operations management and productivity techniques. New Delhi: Prentice-Hall of India

Paton, S. (2001, September). Consumer-driven Six Sigma saves Ford \$300 million. Retrieved October 20, 2010 from http://www.qualitydigest.com/sept01/html/ford.html

Powell. (1995). Total quality management as competitive advantage: A review and empirical study. Strategic Management Journal, 16, 15-37.

Regassa, H., \& Ahmadian, A. (2007). Comparative study of American and Japanese auto industry: General Motors versus Toyota Motors Corporations. The Business Review, Cambridge, 8(1), 1-11. Retrieved October 24, 2010, from ABI/INFORM Global. (Document ID: 1292526201).

Saravanan, R., \& Rao, K. (2006). Development and validation of an instrument for measuring total quality service. Total Quality Management \& Business Excellence, 17(6), 733-749. doi:10.1080/14783360600594487

Scheid, J. (2010, May 26). TQM and Ford Motor Company. Retrieved October 20, 2010 from http://www.brighthub.com/office/project-management/articles/72279.aspx\#ixzz14vhqjPjM

Society of Manufacturing Engineers. (2001, June 13). Ford embraces Six-Sigma quality goals. Retrieved October 31, 2010 from http://www.sme.org/cgi-bin/get-press.pl?\&\&20012513\&ND\&\&SME\&

The National Institute of Standards and Technology. (2010). Criteria for performance excellence. Retrieved October 20, 2010 from http://www.nist.gov/baldrige/publications/business_nonprofit_criteria.cfm

Wharton University of Pennsylvania (2010, February 3). Quality on the line: The fallout from Toyota's Recall. Retrieved October 4, 2010 from http://knowledge.wharton.upenn.edu/article.cfm?articleid=2423

Wharton University of Pennsylvania (2010, March 31). Under the hood of Toyota's recall: 'A tremendous expansion of complexity'. Retrieved October 4, 2010 from

http://knowledge. wharton.upenn.edu/article.cfm?articleid=2462

\section{Biographies}

Dr. Mahesh S. Raisinghani is an associate professor in the Executive MBA program at the TWU School of Management. He is a Certified E-Commerce Consultant (CEC), a Certified Information Security Manager (CISM) and a Project Management Professional (PMP). Dr. Raisinghani was awarded the 2008 Excellence in Research \& Scholarship award and the 2007 G. Ann Uhlir Endowed Fellowship in Higher Education Administration. He was also the recipient of TWU School of Management's 2005 Best Professor Award for the Most Innovative Teaching Methods; 2002 research award; 2001 King/Haggar Award for excellence in teaching, research and service; and a 1999 UD-GSM Presidential Award. He has taught graduate courses at the European University in Switzerland, Turku School of Economics in Finland and Purdue University's German International School of Management and Administration in Germany. He has served as an External Examiner Drof theses and dissertations in Australia and South Africa.

His research has been published in several academic journals such as IEEE Transactions on Engineering Management, Information \& Management, International Journal of Web-based Learning and Teaching Technologies, Information Resources Management Journal, International Journal of Innovation and Learning, Journal of E-Commerce Research, International Journal of Distance Education Technologies, Journal of IT Review, Journal of Global IT Management, and Journal of IT Cases and Applications Research among others and international/national conferences.

He has over 15 years of consulting experience in Fortune 500 Companies in the IT, banking, and service sectors, and and provides management and technical consulting and training to all levels of professionals in both established businesses and new business ventures. Dr. Raisinghani serves on the board of Global IT Management Association and on the education task force of the World 
Affairs Council. He also serves as a Member of the Board of Advisors of Coscend Communications Solutions and CRMG, Inc. He is included in the millennium edition of Who's Who in the World, Who's Who among Professionals, Who's Who among America's Teachers and Who's Who in Information Technology.

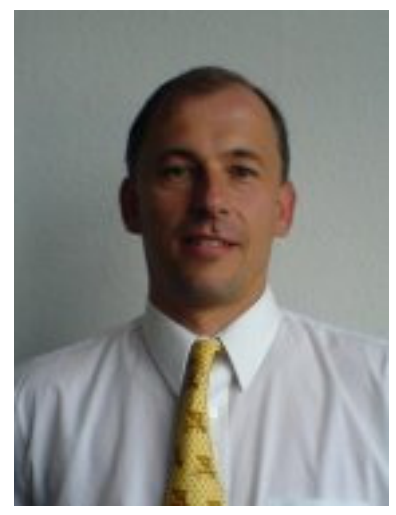

Juergen Georg Kaiser holds a German Diplom degree in Physics from the University of Tuebingen, Germany, and since December 2010, a Master's degree in Information Technology / Project Management from the University of Maryland University College, Adelphi. $\mathrm{He}$ is currently working as a Software Solution Engineer at Ericsson, where he complements his Project Management knowledge with practical project experience. He is involved in cutting edge telecommunication project solutions provided to various large telecommunication companies. He is a member of PMI and his research interests include theoretical foundations of Project Management.

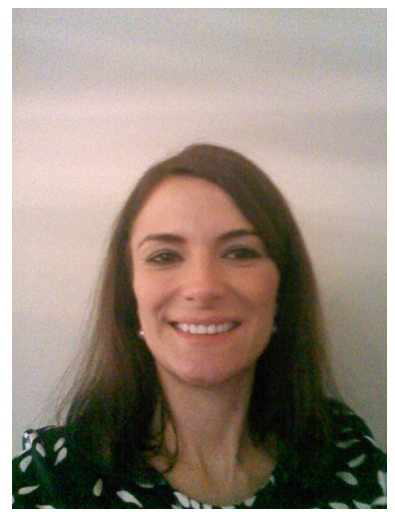

Ms. Tamara Abdulovic is currently the Director of Human Resources at Interfaith Ministries for Greater Houston, providing human resources strategic direction to the organization since March of 2010. Ms. Abdulovic has solid experience in recruiting, hiring, training, staff development, policy and procedures development, change management and strategic positioning in the social services industry.

Ms. Abdulovic entered the HR field in 2005, and since then has held various Human Resources positions at non-profit organizations and for profit companies in Houston. She currently serves on the board of YMCA International Services as the Finance and Board Development Committee member. Ms. Abdulovic is a member of Society for Human Resources Management and HR Houston professional organizations.

Ms. Abdulovic holds a Bachelor's Degree in Finance, with highest honors, from University of St. Thomas in Houston and Executive MBA Degree from Texas Woman's University in Houston.

Ms. Abdulovic is fluent in Serbo-Croatian and is familiar with Spanish language. 